\title{
Simultaneous measurement of hysteresis in capillary pressure and electric permittivity for multiphase flow through porous media
}

\author{
Willem-Jan Plug ${ }^{1}$, Evert Slob ${ }^{1}$, Johannes Bruining ${ }^{1}$, and Leticia M. Moreno Tirado ${ }^{1}$
}

\begin{abstract}
We present a tool that simultaneously measures the complex permittivity and the capillary pressure characteristics for multiphase flow. The sample holder is a parallel plate capacitor. A precision component analyzer is used to measure the impedance amplitude and phase angle as a function of frequency ( $1 \mathrm{kHz}$ to $3 \mathrm{MHz}$ ). The complex impedance of the (partially) saturated sample is directly related to the effective complex permittivity. We have conducted main drainage and main imbibition cycles for unconsolidated sand-water-gas $\left(\mathrm{CO}_{2} / \mathrm{N}_{2}\right)$ systems at 8-bar pressure and at temperatures between $27^{\circ} \mathrm{C}$ and $28^{\circ} \mathrm{C}$. Hysteresis in capillary pressure and electric permittivity, as a result of phase distribution, is found between drainage and imbibition for $f=3 \mathrm{MHz}$ and becomes more pronounced at higher water saturations. Good agreement of the measured electric permittivity with the complex refractive index model indicates that induced polarization is not observed for $3 \mathrm{MHz}$ and the water saturation is reasonably predicted. The experiments have been performed to study the capillary pressure behavior during $\mathrm{CO}_{2}$ sequestration.
\end{abstract}

\section{INTRODUCTION}

Capillary pressure $\left(P_{c}\right)$ versus water saturation $\left(S_{w}\right)$ relationships are used in subsurface flow engineering applications such as hydrocarbon production (Delshad et al., 2003), soil remediation (Dane et al., 1998), and carbon dioxide $\left(\mathrm{CO}_{2}\right)$ sequestration (Plug et al., 2006). Hysteresis between the drainage (decreasing $S_{w}$ ) and imbibition (increasing $S_{w}$ ) of capillary pressure is widely observed and extensively investigated (Morrow, 1970; Hassanizadeh and Gray, 1993; Reeves and Celia, 1996). This saturation history dependence of $P_{c}$ is related to contact angle hysteresis (Anderson, 1986), irreversible pore-scale fluid redistributions (Morrow, 1970), and the in- terfacial area (Reeves and Celia, 1996; Cheng et al., 2004). Because $P_{c}$ is an interfacial property and strongly relates to the pressure and saturation-induced movement and distribution of the phases, the interfacial area per unit volume can be used as an indicator of the thermodynamic energy state (Cheng et al., 2004). This results in a uniquely defined relationship for $P_{c}$ as a function of $S_{w}$ and interfacial area. Furthermore, the initial state of a flow process is involved (van Kats and van Duijn, 2001). Because all these phenomena also contribute to the complex permittivity of porous fluid-bearing rocks, simultaneous measurements of capillary pressure and permittivity may reveal the fundamental physical behavior of capillary pressure hysteresis.

It is known that the complex permittivity may be a function of frequency $f$. Chelidze and Gueguen (1999) distinguish two polarization mechanisms. At frequencies below $10 \mathrm{MHz}$, relaxation processes are exhibited as a result of clustering of components and induced polarization occurring at the solid/fluid interface (Chelidze and Gueguen 1999) and at the interface between the wetting and nonwetting phase (Knight, 1991).

The effects of the pore-scale fluid distribution on the electrical behavior during imbibition and drainage results in hysteresis (Chelidze et al., 1999). Pronounced hysteresis in resistivity is observed by Fleury and Longeron (1998), Knight (1991), Elashahab et al. (1995), and Moss et al. (1999) and can be explained by the percolation theory (Chelidze et al., 1999). Nguyen et al. (1999a) reported on hysteresis of the real part of the permittivity. The change in electrical response as a function of the rock's wettability has been investigated and described by Knight and Abad (1995), Elashahab et al. (1995), Moss et al. (1999), and Nguyen et al. (1999b).

We conclude that different mechanisms are responsible for both the capillary pressure and the complex permittivity behavior. Different studies on combined capillary pressure and electrical resistivity measurements are reported (Elashahab et al., 1995; Fleury and Longeron, 1998; Moss et al., 1999). The real part of the permittivity and capillary pressures were measured simultaneously at frequencies above $100 \mathrm{MHz}$ by Nguyen et al. (1999a).

Manuscript received by the Editor November 10, 2006; revised manuscript received January 9, 2007; published online April 11, 2007.

${ }^{1}$ Delft University of Technology, Faculty of Civil Engineering and Geosciences, Department of Geotechnology, Delft, the Netherlands. E-mail: w.j.plug@tudelft.nl; e.c.slob@tudelft.nl; j.bruining@tudelft.nl; leticia.morenotirado@shell.com. (C) 2007 Society of Exploration Geophysicists. All rights reserved. 
In this study, we investigate the capillary pressure and electric behavior for the unconsolidated sand-distilled-water-gas system during main drainage and main imbibition. The experiments are conducted at 8-bar pressure and a temperature between $27^{\circ} \mathrm{C}$ and $28^{\circ} \mathrm{C}$. We have performed these experiments in the framework of the investigation of capillary pressure behavior during $\mathrm{CO}_{2}$ sequestration applications. The capillary pressure is measured under quasi-static conditions using the setup discussed by Plug et al. (2006). The sample holder is designed as a parallel-plate capacitor (Knight and Nur, 1987; Shen et al., 1987), where two stainless steel end pieces act as electrodes, and different frequencies can be applied $(1 \mathrm{kHz}$ to $3 \mathrm{MHz}$ ). The advantage of this technique over (coaxial) transmission-line methods is that the sample remains intact during the measurements, which is also the case for the coaxial waveguide method (Taherian et al., 1991). Calibration of the impedance tool is done using substances with known complex permittivity values (Shen et al., 1987; Nguyen et al., 1999c) and shows a maximum error of $4.5 \%$ in the real part. Furthermore, the experimental technique is validated with reproducible data, and a precision of $93.5 \%$ is found. Hysteresis in capillary pressure and electric permittivity is observed between drainage and imbibition at $f=3 \mathrm{MHz}$ and becomes more pronounced at higher water saturations. Comparison of the data with the complex refractive index model shows the reasonable prediction for the water saturation. Finally, we suggest that a better description of the capillary pressure hysteresis can be obtained from accurate permittivity data than from water saturation alone.

\section{EXPERIMENTAL METHOD AND MATERIALS}

The experimental setup is based on the porous plate technique (Plug et al., 2006). We apply quasi-static conditions (Wildenschild et al., 2001), i.e., small injection rates, so that viscous forces can be neglected. A schematic overview of the experimental setup is shown in Figure 1. Two syringe pumps are used and can be set to a constant injection rate or a constant pressure. The gas and the water phases are injected or produced at the top and the bottom of the sample holder, respectively. The pressure difference between the gas and the water phase is measured by a pressure-difference transducer (PDT, accuracy $\pm 0.05 \mathrm{mbar}$ ), which is located at the same height as the middle of

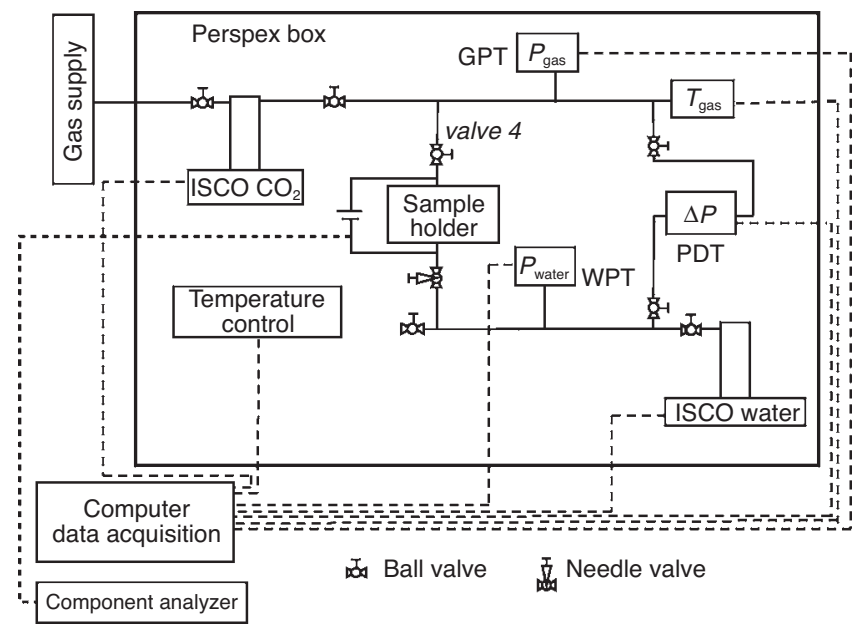

Figure 1. Schematic layout of the experimental setup. PDT: pressure difference transducer; GPT: gas pressure transducer; WPT: water pressure transducer. the sample. A temperature control system is used to maintain a constant temperature.

The sample holder, (see Figures 2 and 3), consists of three parts: a polyetheretherketone (PEEK) ring, which contains the sand sample, and two stainless steel end pieces. Two porous plates (SIPERM $R$, Cr-Steel basis), with a permeability of $2 \times 10^{-12} \mathrm{~m}^{2}$ and a porosity of 0.32 , support the sample and protect the hydrophilic membrane. Two stainless steel plates, both with 32 perforations $\left(D_{p}=5 \mathrm{~mm}\right)$, are used at the top, directly above the sample, in combination with a nylon filter. Concentric flow grooves in the end pieces redistribute the phases over the sample area to avoid preferential flow. The different parts of the sample holder are mounted together with four stainless steel bolts at both the top and bottom.

To obtain the permittivity of the sample inside the PEEK ring, a precision component analyzer (Wayne-Kerr, 6640A) is connected to the sample holder (Figure 1). The electrodes are the two end pieces of the sample holder, including the support plates. The PEEK material is nonconductive and, hence, the sample holder acts as a parallelplate capacitor. The impedance amplitude, $|Z|[\Omega]$, and the phase angle, $\theta[\mathrm{rad}]$, are measured as a function of the frequency and are directly related to the effective complex permittivity $\left(\varepsilon_{s}^{*}\right)$ of the sample, defined by $\varepsilon_{s}^{*}=\varepsilon_{s}^{\prime}-i \varepsilon_{s}^{\prime \prime}$. Here, $\varepsilon_{s}^{\prime}$ and $\varepsilon_{s}^{\prime \prime}$ represent the real and imaginary part of the permittivity, respectively. In this study, we are interested in $\varepsilon_{s}^{\prime}$, and the results are presented as a function of $S_{w}$.

\section{DATA ANALYSIS}

We define the capillary pressure as the difference in gas and water bulk phase pressures. From the produced water volume we obtain the water saturation. The complex capacitance $C^{*}[\mathrm{~F}]$ is inversely proportional to the complex impedance $Z^{*}[\Omega]$ by $C^{*}=\left(i \omega Z^{*}\right)^{-1}$, where $\omega$ is the angular frequency, defined by $\omega=2 \pi f$, and $Z^{*}$ $=|Z| \exp (i \theta)$. The capacitor configuration results in a parallel circuit

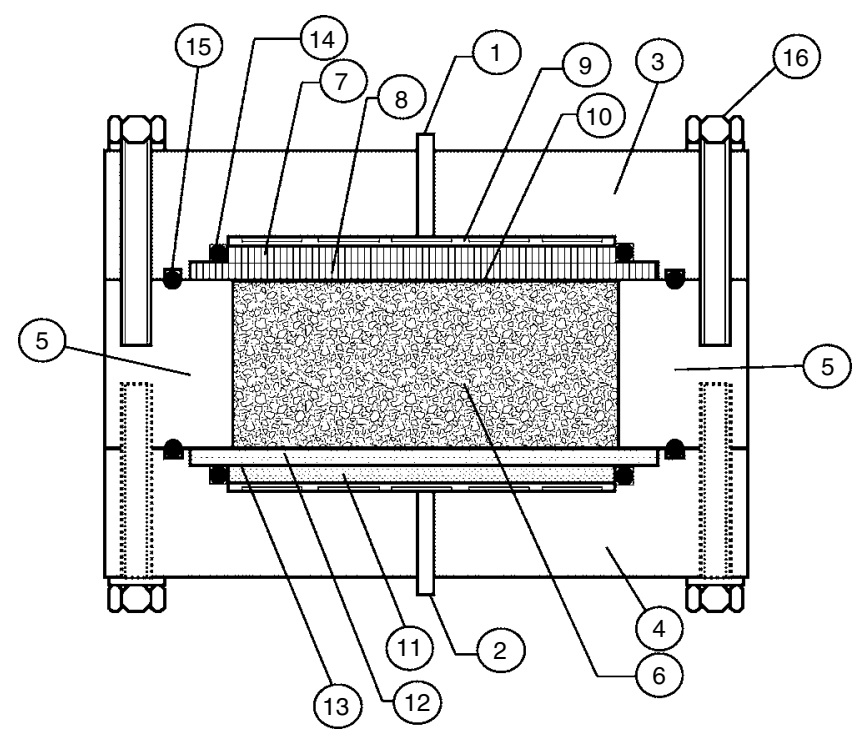

Figure 2. The sample holder: 1. Gas inlet; 2. Water inlet; 3 . Stainless steel end piece $1 ; 4$. Stainless steel end piece 2; 5. PEEK ring; 6. Porous medium (diameter is $84 \mathrm{~mm}$, height is $27 \mathrm{~mm}$ ); 7. Perforated plate (diameter is $84 \mathrm{~mm}$ ); 8 . Perforated plate (diameter is $90 \mathrm{~mm}$ ); 9. Concentric grooves; 10 . Nylon filter (pore size $210 \mu \mathrm{m}$ ); 11. SIPERM plate (diameter is $84 \mathrm{~mm}$ ); 12. SIPERM plate (diameter is $90 \mathrm{~mm}$ ); 13. Water-wet filter (pore size $0.1 \mu \mathrm{m}) ; 14$. O-rings $(2.1 \mathrm{~mm}) ; 15$. O-rings ( $4 \mathrm{~mm}) ; 16$. Stainless steel bolts. 
for which $C^{*}$ is considered as the sum of the capacitance of the sample $\left(C_{s}^{*}\right)$, the PEEK ring $\left(C_{\mathrm{PEEK}}^{*}\right)$, the cables $\left(C_{\text {cables }}^{*}\right)$, the electrodes design $\left(C_{\text {electrodes }}^{*}\right)$, and the background noise $\left(C_{\text {noise }}^{*}\right)$. Under the assumption that only $C_{s}^{*}$ is changing for different samples, $C^{*}$ can be written as

$$
C^{*}=C_{s}^{*}+C_{\text {residual }}^{*}=\frac{\varepsilon_{0} \varepsilon_{s}^{*} A_{s}}{H}+C_{\text {residual }}^{*} \text {. }
$$

Here, $\varepsilon_{0}$ is the permittivity of free space, $\varepsilon_{s}^{*}$ is the permittivity of the sample, $C_{\text {residual }}^{*}[\mathrm{~F}]$ is the capacitance of the residual contributions, and $H[\mathrm{~m}]$ and $A_{s}\left[\mathrm{~m}^{2}\right]$ are, respectively, the height and the cross-sectional area of the sample. We use the complex refractive index (CRI) model (Roth et al., 1990; Seleznev et al., 2004) to evaluate the effective permittivity of the grain-water-gas mixture, given by

$$
\varepsilon_{s}^{\prime}=\left[\phi S_{w} \sqrt{\varepsilon_{w}^{\prime}}+\phi\left(1-S_{w}\right) \sqrt{\varepsilon_{\text {gas }}^{\prime}}+(1-\phi) \sqrt{\varepsilon_{\text {grain }}^{\prime}}\right]^{2},
$$

where $\varphi$ is the porosity; and $\varepsilon_{w}^{\prime}, \varepsilon_{\text {gas }}^{\prime}$, and $\varepsilon_{\text {grain }}^{\prime}$ are the water, gas, and porous medium permittivities, respectively. Furthermore, the Hashin-Shtrikman bounds (Hashin and Shtrikman, 1962) are used to investigate the validity of the results. The Hashin-Shtrikman bounds put limits on the effective electric permittivity of locally noninteract-

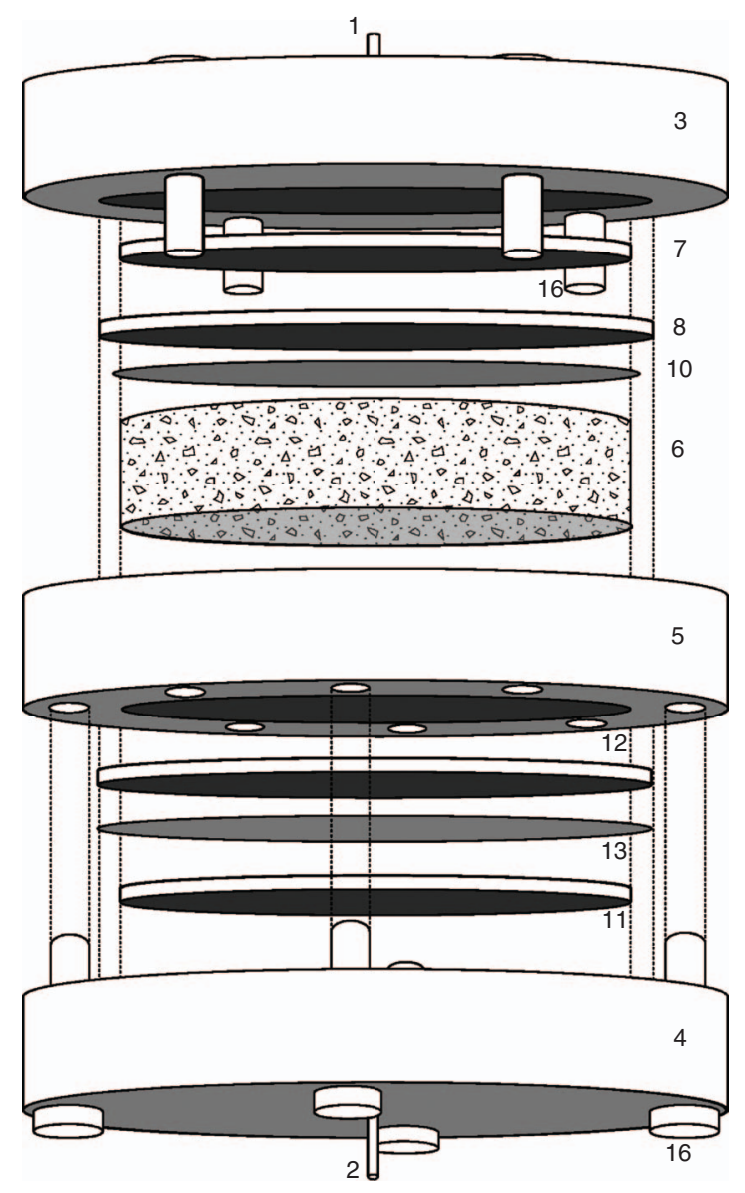

Figure 3. Three-dimensional representation of the sample holder (not to scale). The numbers correspond to the legend of Figure 2. For visualization reasons, the rubber O-rings and the concentric grooves are not shown. ing and macroscopically homogeneous, isotropic mixtures. Our sand samples satisfy these conditions.

\section{CALIBRATION AND SYSTEM ACCURACY}

To obtain the most accurate data for the permittivity and the capillary pressure, different configurations of the sample holder are investigated. It appears that the type and combination of the support plates and the presence and number of the stainless steel bolts do not influence the impedance measurements.

The value for $C_{\text {residual }}^{*}$ (equation 1) is obtained from air measurements using $\varepsilon_{s}^{\prime}=1$. The capacitance $C^{*}$, of the air-filled sample holder is measured in the range of 20 to $21 \pm 0.05 \mathrm{pF}$ for the frequency range of $1 \mathrm{kHz}$ to $3 \mathrm{MHz}$. A statistical analysis on 50 measurements (Gorriti and Slob, 2005), for air and six different calibration materials, (see Table 1), is performed to determine the maximum measurement accuracy. It appears that the measurements are very stable. The mean and the relative error for both $|Z|$ and $\theta$ of ten groups of two air measurements are of the order of $0.1 \%$.

The impedance tool is calibrated for $f=3 \mathrm{MHz}$ using materials with known permittivity behavior within the range of 2 to 25 . In Table 1 , we present the theoretical permittivities $\varepsilon_{s, \text { theory }}^{\prime}$, the measured permittivities and the absolute errors $\Delta \varepsilon_{s}^{\prime}$ obtained from an error analysis, and the accuracy of the 50 measurements for each calibration sample. High accuracy and good agreement is found for a wide range of permittivity values.

\section{SAMPLE PREPARATION AND EXPERIMENTAL PROCEDURE}

We investigate the capillary pressure and complex permittivity behavior of the unconsolidated sand-water-gas $\left(\mathrm{CO}_{2} / \mathrm{N}_{2}\right)$ system. For each experiment, a new sand pack is used. The average grain size fraction is 360 to $410 \mu \mathrm{m}$, and the porosity is obtained with helium at room temperature. For all samples, the porosity varies from 0.37 to $0.38 \pm 0.005$.

After the porosity measurements, the total system is evacuated for 1 hour. Subsequently, the sample holder is filled with distilled water (no salinity) at a pressure of approximately 8 bar to dissolve small air bubbles. Valve 4 (see Figure 1) is closed and the gas tubing and pump are filled with gas. The gas booster is used to bring up the gas pressure. We set a constant temperature and let the system equilibrate for two days. When both the water and gas pressures are equal, a constant water refill rate is applied, the gas pump is set to a constant pres-

Table 1. Theoretical and measured permittivity values and their corresponding error and accuracy for the calibration samples at $f=3 \mathrm{MHz}$ and $25^{\circ} \mathrm{C}$. The theoretical values are obtained from Weast and Astle (1981).

\begin{tabular}{lccc}
\hline Sample & \multicolumn{1}{c}{$\boldsymbol{\varepsilon}_{s, \text { theory }}^{\prime}$} & $\boldsymbol{\varepsilon}_{s}^{\prime} \pm \Delta \boldsymbol{\varepsilon}_{s}^{\prime}$ & Accuracy of $\boldsymbol{\varepsilon}_{s}^{\prime}$ \\
\hline Teflon & $2.00(1 \mathrm{MHz})$ & $2.06 \pm 0.03$ & $99.5 \%$ \\
Perspex & $2.76(1 \mathrm{MHz})$ & $2.84 \pm 0.04$ & $98.9 \%$ \\
PVC & $3.30(1 \mathrm{MHz})$ & $3.32 \pm 0.04$ & $99.3 \%$ \\
1-Decanol $(99 \%)$ & $8.10($ static $)$ & $8.49 \pm 0.05$ & $99.8 \%$ \\
1-Butanol & 17.80 (static) & $18.32 \pm 0.06$ & $99.9 \%$ \\
Ethanol $(100 \%)$ & 24.30 (static) & $24.64 \pm 0.07$ & $99.8 \%$ \\
\hline
\end{tabular}


a)

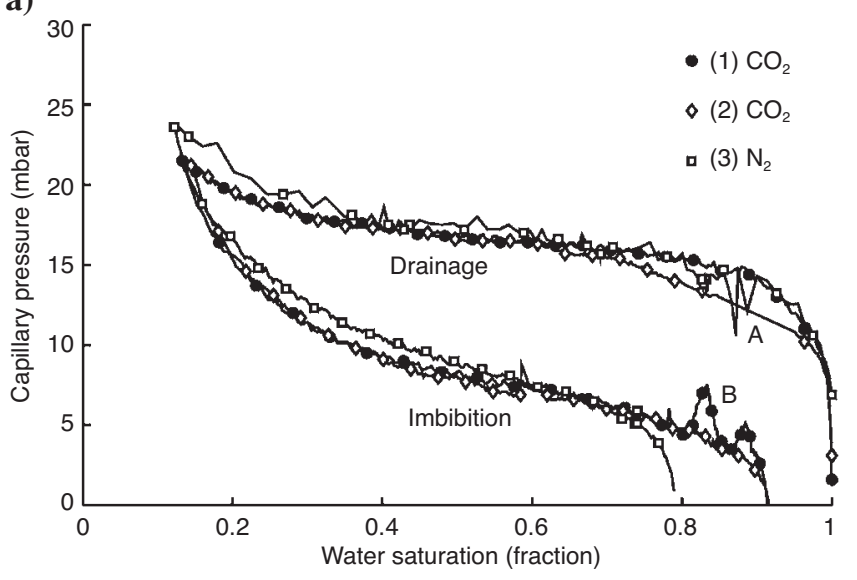

b)

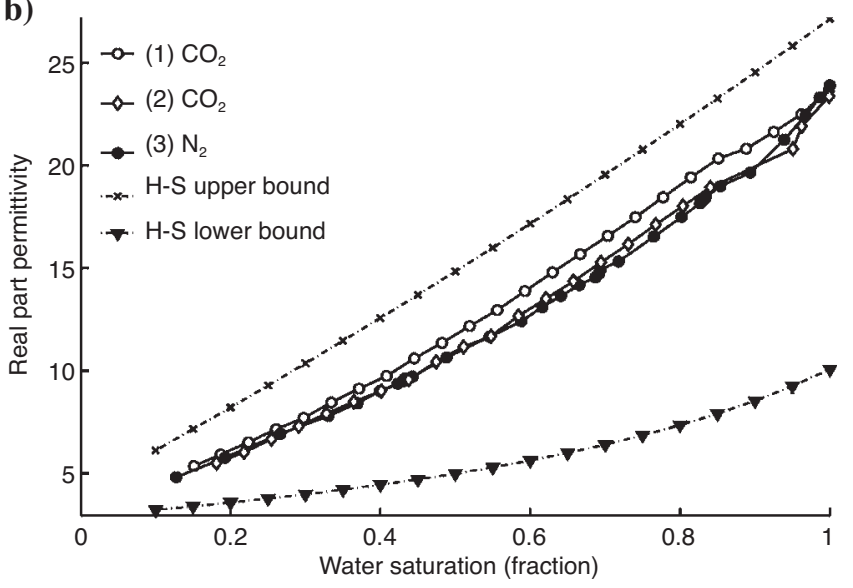

c)

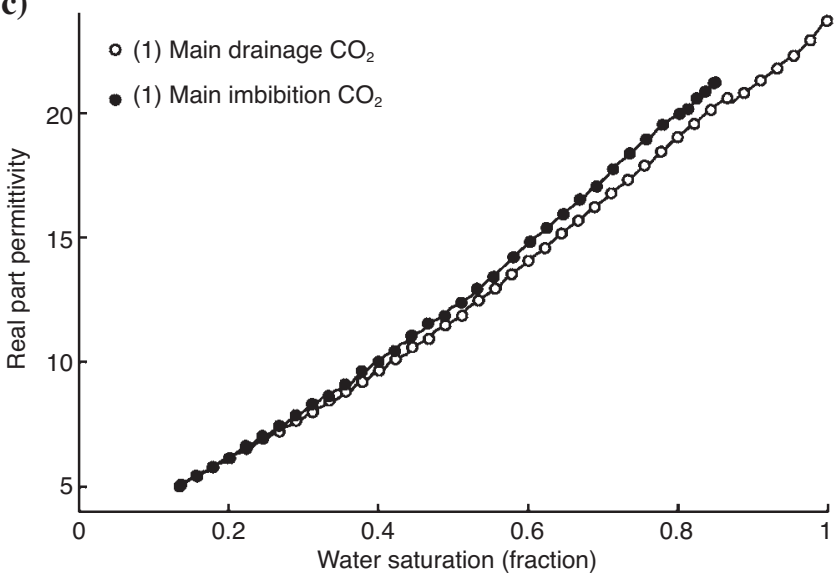

Figure 4. Main drainage and imbibition capillary pressure curves (a) for $\mathrm{CO}_{2}$ and $\mathrm{N}_{2}$ for a flow rate of $0.5 \mathrm{ml} / \mathrm{h}$. The curves for $\mathrm{CO}_{2}$ coincide, which clarifies the reproducibility of the method. The corresponding real part of the permittivity $\varepsilon_{s}^{\prime}$ as a function of $S_{w}$ for the main drainage experiments are shown in (b) as well as the HashinShtrikman upper and lower bounds. For experiment $1\left(\mathrm{CO}_{2}-\right.$ distilled water-sand), the real part of the permittivity is shown in (c) for both the main drainage and imbibition process. The hysteresis in permittivity is clearly visible. All experiments are conducted for pressures of $8 \mathrm{bar}$ and a temperature of $27^{\circ} \mathrm{C}$ and $28^{\circ} \mathrm{C}$ for, respectively, $\mathrm{CO}_{2}$ and $\mathrm{N}_{2}$. sure, and valve 4 is opened. After the main drainage process, the main imbibition process starts when the water pump is set to a constant injection rate.

\section{RESULTS AND DISCUSSION}

Figure 4a shows the capillary pressure as a function of the water saturation for the $\mathrm{CO}_{2}$-water-sand and the $\mathrm{N}_{2}$-water-sand systems. Both of the $\mathrm{CO}_{2}$ experiments are performed at 8 bar and $28^{\circ} \mathrm{C}$ and show good reproducibility. The relative error for the water saturation calculation is $\pm 12 \%$ for $S_{w}=0.1$ and decreases towards zero for $S_{w}$ $=1$. For visualization reasons, the error bars for $S_{w}$ are not shown in Figure 4a. High precision in capillary pressure is obtained for the saturation range between 0.15 and 0.72 . As a result of a power failure at A (Figure 4a), the primary drainage data are missing near $S_{w}=0.9$ for experiment 2 . The nonmonotonic behavior of the imbibition curve, observed at point B (experiment 1), is attributed to summer temperatures in the laboratory that exceeded the upper limit of the temperature control system. Capillary pressure hysteresis is measured and is similar for both experiments. The experiment with nitrogen $\left(\mathrm{N}_{2}\right)$ is conducted at 8 bar, and a temperature of $27^{\circ} \mathrm{C}$ is applied. Both the drainage and imbibition curves are slightly higher than those for $\mathrm{CO}_{2}$ for $S_{w}<0.6$, and a higher residual gas saturation $\left(S_{g r}\right.$ $=0.21)$ is obtained. The difference in residual gas saturation is explained by higher dissolution of $\mathrm{CO}_{2}$ in water.

In Figure $4 \mathrm{~b}, \varepsilon_{s}^{\prime}$ as function of $S_{w}$, for the main drainage processes is shown for $f=3 \mathrm{MHz}$. The measurement data can be fitted with the CRI (equation 2) model using $\varepsilon_{w}^{\prime}=80, \varepsilon_{\text {grain }}^{\prime}=6$, and $\varepsilon_{\text {gas }}^{\prime}=1$ for water, grains, and $\mathrm{CO}_{2} / \mathrm{N}_{2}$, respectively. This indicates that $S_{w}$ is predicted reasonably from the measurements. Because the sample porosities are between 0.37 and 0.38 , the porosity used in CRI is $\phi$ $=0.375$. From Figure $4 \mathrm{~b}$ it is clear that the measured effective permittivities satisfy the Hashin-Shtrikman bounds. This implies that for $f=3 \mathrm{MHz}$, the system can be considered to be a macroscopically homogeneous and isotropic mixture.

From the drainage data of the two $\mathrm{CO}_{2}$ experiments (Figure 4b), we obtain the reproducibility of the permittivity measurements. A precision of $93.5 \%$ is determined for the water saturation range of $0.15<S_{w}<0.72$, which is lower than the precision for the $P_{c}$ curves. This is caused by difference in sand packs.

Figure $4 \mathrm{c}$ plots $\varepsilon_{s}^{\prime}$ for the main drainage and imbibition processes for the first $\mathrm{CO}_{2}$ experiment. The same input parameters for the CRI model used for the drainage process result in good agreement for imbibition. It is clear that the Hashin-Shtrikman bounds are still satisfied for imbibition. Comparison between the curves in Figure $4 \mathrm{c}$ shows that $\varepsilon_{s}^{\prime}$ for imbibition is higher than for drainage. Similar to the capillary pressure hysteresis, the permittivity hysteresis increases for increasing water saturation.

Near $S_{w}=0.85$, the slope of $\varepsilon_{s}^{\prime}$ in each drainage experiment shows an abrupt change (Figure 4b). As a result of spontaneous redistribution of the phases and percolation mechanisms, the system undergoes a transition from trapped gas to trapped water (Knight, 1991; Chelidze et al., 1999). The clear dip in drainage, $P_{c}$ at $S_{w}=0.85$, for experiment 3 supports this explanation. Similar permittivity behavior is also observed for the imbibition process near $S_{w}=0.8$ (see Figure $4 \mathrm{c})$.

Reasons for the permittivity hysteresis can be found in the distribution of the water and gas phase (Chelidze et al., 1999) as well as in the change in interfacial area during drainage and imbibition. The first effect mentioned is observed in this study, the latter effect is ex- 
pected to be more pronounced for lower frequencies. Different mechanisms, such as dipole polarization, polarization in the electrical double layer (Chelidze et al., 1999), and conduction on the watergas interface (Knight, 1991) are, therefore, considered to be the key to improve the current knowledge of capillary hysteresis as a function of the interfacial area, especially when pronounced permittivity hysteresis is observed at high water contents.

\section{CONCLUSIONS}

The measurements presented in this work show that it is possible to measure the capillary pressure and the permittivity properties simultaneously with a nondestructive technique. The tool is widely applicable and can be used for fluid-bearing rocks and soils, and the results are, therefore, relevant for applications in near-surface as well as exploration and production geophysics. Moreover, the experimentally observed hysteresis in the real part of the complex electric permittivity provides evidence that a better description of the capillary pressure hysteresis can be obtained than that from water saturation alone. Because the presence of water plays a dominant role in the permittivity behavior, low frequency measurements are necessary to assist in the interpretation of the permittivity hysteresis in terms of interfacial activities.

\section{ACKNOWLEDGMENTS}

The research presented in this work was carried out as part of the CATO program: $\mathrm{CO}_{2}$ Capture, Transport and Storage in the Netherlands (http://www.CO2-cato.nl/) and the DIOC water project. The financial support is gratefully acknowledged. We thank L. Vogt, P. S. A. de Vreede, H. G van Asten, and H. K. J. Heller for technical support. We thank the reviewers for their constructive remarks.

\section{REFERENCES}

Anderson, W. G., 1986, Wettability literature survey - Part 2: Wettability measurement: Journal of Petroleum Technology, 1246-1262.

Chelidze, T. L., and Y. Gueguen, 1999, Electrical spectroscopy of porous rocks: A review - I. Theoretical model: Geophysical Journal International, 137, 1-15.

Chelidze, T. L., Y. Gueguen, and C. Ruffet, 1999, Electrical spectroscopy of porous rocks: A review - II. Experimental results and interpretation: Geophysical Journal International, 137, 16-34.

Cheng, J.-T., L. J. Pyrak-Nolte, D. D. Nolte, and N. J. Giordano, 2004, Linking pressure and saturation through interfacial areas in porous media: Geophysical Research Letters, 31, L08502; http://dx.doi.org/10.1029/ 2003GL019282.

Dane, J. H., C. Hofstee, and A. T. Corey, 1998, Simultaneous measurement of capillary pressure, saturation, and effective permeability of immiscible liquids in porous media: Water Resources Research, 34, 3687-3692.

Delshad, M., R. J. Lenhard, M. Oostrom, and G. A. Pope, 2003, A mixed-wet hysteretic relative permeability and capillary pressure model for reservoir simulations: SPE Reservoir Evaluation and Engineering, 6, 328-334.

Elashahab, B. M., X. D. Jing, and J. S. Archer, 1995, Resistivity index and capillary pressure hysteresis for rock samples of different wettability characteristics: Presented at the SPE Middle East Oil Show, Paper 29888.

Fleury, M., and D. Longeron, 1998, Combined resistivity and capillary pressure measurements using micropore membrane technique: Journal of Petroleum Science and Engineering, 19, 73-79.

Gorriti, A. G., and E. C. Slob, 2005, A new tool for accurate $S$-parameters measurements and permittivity reconstruction: IEEE Transactions on Geoscience and Remote Sensing, 43, 1727-1735.

Hashin, Z., and S. Shtrikman, 1962, A variational approach to the theory of the effective magnetic permeability of multiphase materials: Journal of Applied Physics, 33, 3125-3131.

Hassanizadeh, S. M., and W. G. Gray, 1993, Thermodynamic basis of capillary pressure in porous media: Water Resources Research, 29, 3389-3405.

Knight, R., 1991, Hysteresis in the electrical resistivity of partially saturated sandstones: Geophysics, 56, 2139-2147.

Knight, R., and A. Abad, 1995, Rock/water interaction in dielectric properties: Experiments with hydrophobic sandstones: Geophysics, 60, 431-436.

Knight, R. J., and A. Nur, 1987, The dielectric constant of sandstones, $60 \mathrm{kHz}$ to $4 \mathrm{MHz}$ : Geophysics, 52, 644-654.

Morrow, N., 1970, Physics and thermodynamics of capillary action in porous media: Industrial and Engineering Chemistry, 62, 32-56.

Moss, A. K., X. D. Jing, and J. S. Archer, 1999, Laboratory investigation of wettability and hysteresis effects on resistivity index and capillary pressure characteristics: Journal of Petroleum Science and Engineering, 24, 231-242.

Nguyen, B.-L., J. Bruining, and E. C. Slob, 1999a, Hysteresis in dielectric properties of fluid-saturated porous media: Presented at the SPE Asia Pacific Improved Oil Recovery Conference, Paper 57305.

, 1999b, Effects of wettability on dielectric properties of porous media: Presented at the SPE Annual Technical Conference and Exhibition, Paper 56507.

Nguyen, B.-L., A. M. Geels, J. Bruining, and E. C. Slob, 1999c, Calibration measurements of dielectric properties of porous media: SPE Journal, 4 353-359.

Plug, W. J., S. Mazumder, J. Bruining, K. H. A. A. Wolf, and N. Siemons, 2006, Capillary pressure and wettability behavior of the coal-water-carbon dioxide system at high pressures: Presented at the International CBM Symposium, Paper 606

Reeves, P. C., and M. A. Celia, 1996, A functional relationship between capillary pressure, saturation and interfacial area as revealed by a pore-scale network model: Water Resources Research, 32, 2345-2358.

Roth, K., R. Schulin, H. Flühler, and W. Attinger, 1990, Calibration of time domain reflectometry for water content measurement using a composite dielectric approach: Water Resources Research, 26, 2267-2273.

Seleznev, N., A. Boyd, T. Habashy, and S. Luthi, 2004, Dielectric mixing laws for fully and partially saturated carbonate rocks: Proceedings of the SPWLA 45th Annual Symposium, Paper CCC.

Shen, L. C., H. Marouni, Y. Zhang, and X. Shi, 1987, Analysis of the paralleldisk sample holder for dielectric permittivity measurement: IEEE Transactions on Geoscience and Remote Sensing, 25, 534-539.

Taherian, M. R., D. J. Yuen, T. L. Habashy, and J. A. Kong, 1991, A coaxialcircular waveguide for dielectric measurement: IEEE Transactions on Geoscience and Remote Sensing, 29, 321-329.

van Kats, F. M., and C. J. van Duijn, 2001, A mathematical model for hysteretic two-phase flow in porous media: Transport in Porous Media, 43, 239 263.

Weast, R. C., and M. J. Astle, 1981, CRC handbook of chemistry and physics, 62nd ed.: CRC Press.

Wildenschild, D., J. Hopmans, and J. Simunek, 2001, Flow rate dependence of soil hydraulic characteristics: Soil Science Society of America Journal, 65, 35-48. 